\title{
[Technical Paper]
}

\section{Immersion Cooling of Electronics Utilizing Lotus-Type Porous}

\section{Copper}

\author{
Kazuhisa Yuki*, Tomohiro Hara*, Soichiro Ikezawa*, Kentaro Anju*, Koichi Suzuki*, Tetsuro Ogushi**,***, \\ Takuya Ide***, and Masaaki Murakami** \\ *Tokyo University of Science-Yamaguchi, Yamaguchi 756-0884, Japan \\ **Advanced Knowledge Laboratory, Inc., 1-20 Sumiyoshicho, Shinjuku-ku, Tokyo 162-0065, Japan \\ ***Institute for Lotus Materials Research Co. Ltd., 1-1-3-267 Umeda, Kitaku, Osaka 530-0001, Japan
}

(Received August 19, 2016; accepted December 19, 2016, published December 26, 2016)

\begin{abstract}
This paper evaluates boiling heat transfer performance on a lotus-type porous copper plate attached onto a heated surface. The experiments are performed under atmospheric and saturated pool conditions. The lotus copper plates have uni-directional pore structure in a perpendicular direction for the heated surface and the average hydraulic diameter of the pore hole is $0.36 \mathrm{~mm}$. The lotus copper plate of $1.0 \mathrm{~mm}$ or $2.0 \mathrm{~mm}$ in thickness is mechanically attached or soldered onto the heated surface in order to obtain the referential boiling heat transfer data of utilizing the lotus copper plate. The boiling curves suggest that the utilization of the lotus copper plate leads to boiling heat transfer enhancement especially in a low heat flux regime even when the lotus copper is mechanically attached to the heat transfer surface. However, the thickness of the lotus plate doesn’t affect the boiling heat transfer in the mechanically attached case, which indicates that there is a big contact thermal resistance between the heated surface and the lotus copper plate. In addition, it is confirmed that the critical heat flux in the mechanically attached case is almost the same as that in the smooth surface case. On the other hand, the critical heat flux increases up to $216 \mathrm{~W} / \mathrm{cm}^{2}$ by soldering the lotus copper plate to the heated surface, which is almost double of that in the smooth surface case.
\end{abstract}

Keywords: Immersion Cooling, Electronics, Lotus Porous Copper, Critical Heat Flux, Saturated Pool Boiling

\section{Introduction}

Recent advancement in electronics has increased the heat generation from the chip and brought up again various issues regarding the thermal management. Among the issues, reduction in thermal resistance around the chip with high thermal conductivity TIM (Thermal Interface Material), high performance of heat spreader, heat transport and cooling technologies, etc. is still one of the most important issues that contributes to long-term stable and safe operation of the electronics. Focusing on high heat generation of the electronics, the heat flux from the chip of high performance computers has been increasing toward $100 \mathrm{~W} / \mathrm{cm}^{2}$ and, in fact, the heat flux of the $\mathrm{K}$ supercomputer already exceeded $70 \mathrm{~W} / \mathrm{cm}^{2}$.[1] Furthermore, the heat flux from the next generation SiC-based inverters equipped for the fuel-cell vehicles and the electric vehicles is much higher than that of the present vehicles and will come up to $300 \mathrm{~W} / \mathrm{cm}^{2}$ in the near future although it is local and not in a steady state.[2] Against such a high heat flux, liquid cooling based on forced convective heat transfer with minichannel finned heat sinks[3-10] are commonly introduced to increase the heat transfer coefficient by an expansion of the heat transfer surface and flow-channel narrowing effect. In order to construct an energy-saving cooling system, however, it needs to develop novel cooling technologies with low pumping power or pumpless systems.

In order to construct the pump-less cooling system, a wide variety of heat transport devices such as heat pipes and vapor chambers have been introduced for various electronics. The greatest advantage of utilizing these heat transport devices based mainly on evaporative heat transfer is that they enable self-liquid-supply driven by capillary force induced in the fine pore of the porous wicks. These heat transport technologies are currently introduced for cutting-edge high-performance personal computers, 
smartphones, etc. However, these heat transport devices have the heat transport limit that results from a trade-off relationship between the capillary force and the friction loss in the porous wick. Furthermore, from the viewpoint of the heat flux, these evaporative heat transport devices don't work due to the boiling limit under high heat flux conditions and are commonly utilized way below 100 $\mathrm{W} / \mathrm{cm}^{2}$. To cope with the difficulty regarding the high heat flux removal, much attention has been turned to a cooling device such as thermosiphons etc, in which the heated surface is immersed into liquid for cooling to utilize the boiling heat transfer. Although the boiling immersion cooling still has some issues such as overshoot of the surface temperature which arises at the beginning of the nucleate boiling regime, the critical heat flux of water under atmospheric and saturated pool boiling conditions exceeds $100 \mathrm{~W} / \mathrm{cm}^{2}$. In order to apply the boiling heat transfer to the high heat generation electronics with the heat flux over $100 \mathrm{~W} / \mathrm{cm}^{2}$, a wide variety of passive heat transfer enhancement technologies have been proposed to enhance both the nucleate boiling heat transfer and the critical heat flux. One of them is the application of porous media.[11-19] The installation of the porous media onto the heated surface has the following advantages: (1) expansion of the heat transfer area, (2) enhancement of nucleate boiling heat transfer by increase in nucleation sites, and (3) autonomous liquid supply toward the heat transfer surface by capillary force. Many previous studies have confirmed that the installation of the porous media which are properly designed on the heated surface can make it possible not only to enhance the nucleate boiling heat transfer, namely to reduce temperature difference between the chip and the cooling liquid, but also to increase the critical heat flux by adjusting the pore diameters or the thickness.

Although the porous media can be generally classified into particle-sintered porous media, porous foam, fibrous porous media, porous mesh, etc., lotus porous media with uni-directional porous structure have been developed recently. [20,21] The feature of the lotus porous media is higher effective thermal conductivity in the pore direction and higher permeability due to the uni-directional pore structure, compared with the other porous media as shown in Fig. 1, which conceivably leads to further enhancement of the boiling heat transfer due to high fin effect. Furthermore, adjusting the porosity and the pore size is easier compared with the other porous media, which makes sure to find the optimal porous structure to

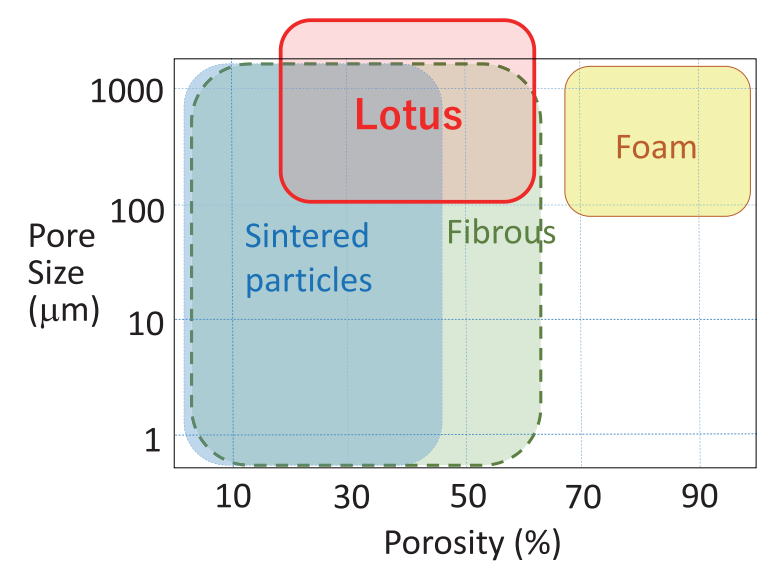

Fig. 1 Various kinds of porous media.

increase the critical heat flux toward $300 \mathrm{~W} / \mathrm{cm}^{2}$. In this study, the lotus porous media that are mechanically attached or soldered onto the heat transfer surface are introduced to saturated pool boiling system in order to obtain the referential boiling heat transfer data of utilizing the lotus porous media. Summarizing the boiling heat transfer characteristics obtained, we discuss the availability, the issues, and the future perspectives of utilizing the lotus porous media to the high heat flux electronics.

\section{Experimental Setup}

Figure 2 shows the schematic of the experimental apparatus. The experimental apparatus mainly consists of the heat transfer block, the glass vessel, and the condenser. Distilled water is used as the cooling liquid. The pool boiling experiments are conducted under the atmospheric and saturated conditions. The top surface of the heat transfer block, which is shown on the lower right of Fig. 2, is the heat transfer surface with 10 by 10 millimeters square. In the bottom part of the heat transfer block, four cartridge heaters are inserted to adjust the heat flux at the heat transfer surface by controlling the voltage applied to each heater. Four K-type-thermocouples of $0.5 \mathrm{~mm}$ in diameter are embedded at the central axis of the square rod of the heat transfer block, in order to evaluate the temperature profile in the square rod, the wall superheat, and the heat flux at the heat transfer surface. The glass vessel is wound with a heater around it to keep the cooling liquid at saturated temperature. The inner diameter and the height of the glass vessel are $55 \mathrm{~mm}$ and $100 \mathrm{~mm}$, respectively. The height of the liquid level is approximately $90 \mathrm{~mm}$. On the top of the glass vessel, the condenser, which is cooled by tap water, is equipped to condense the vapor generated during the experiment. The condenser has a small air vent, so that the pressure in the glass vessel is kept at atmo- 


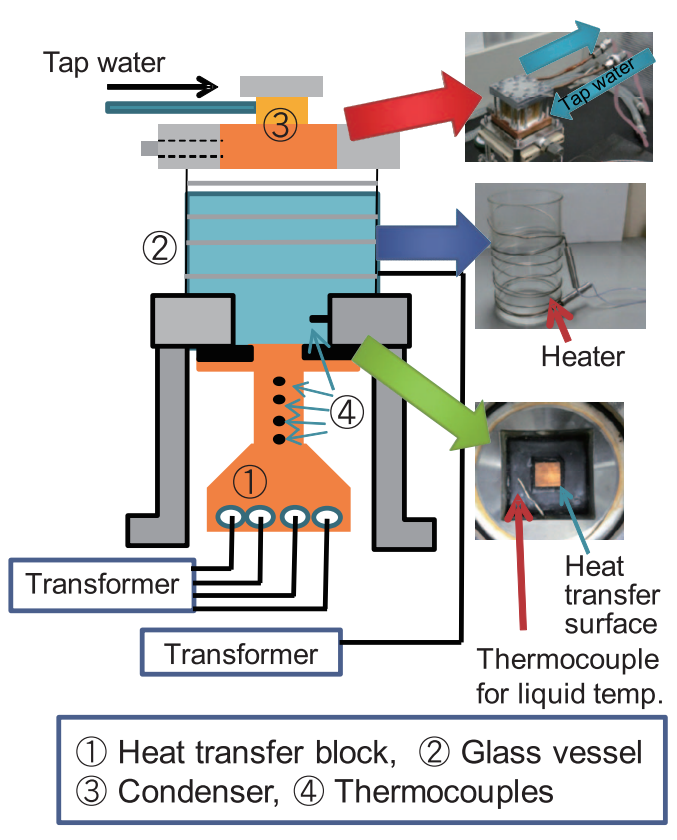

Fig. 2 Experimental setup.

spheric pressure during the experiment.

The lotus porous media in the shape of a plate that we introduced are made of copper and have the same area with 10 by 10 millimeters square as the heat transfer surface (hereafter, lotus copper plate). The thicknesses are $1.0 \mathrm{~mm}$ and $2.0 \mathrm{~mm}$. The lotus copper plate has uni-directional and mostly open pore structure. The average hydraulic pore diameter, which is estimated by assuming the lotus holes as an ellipse, is $0.36 \mathrm{~mm}$. The porosity is 0.36. In general, the porous media with the pore size less than $0.1 \mathrm{~mm}$ is desirable in order to make use of the capillary phenomenon. However, we decided to use a larger hole of lotus porous media because discharging the vapor outside the porous medium is essential under high heat flux conditions. In addition, this hole size doesn't work as the cavity for boiling. Figure 3 shows the surface structure of the lotus copper plate, in close-up, with a microscope. This surface is polished with a \#2000 emery paper to reduce contact thermal resistance between the lotus copper plate and the heat transfer surface. The lotus copper plate is mechanically attached with a spring or soldered onto the heat transfer surface. The length and the external diameter of the spring are $50 \mathrm{~mm}$ and $10 \mathrm{~mm}$, respectively. This spring is inserted around a stainless-steel bolt of 6 $\mathrm{mm}$ in diameter which is fixed to the condenser (See Fig. 4) and mechanically pushes the lotus copper plate to the heat transfer surface. The restoring force of the spring is set to $39 \mathrm{kPa}$, taking into consideration deformation of the spring. Furthermore, in order to confirm the effect of the liquid supply toward the lotus holes on the boiling heat
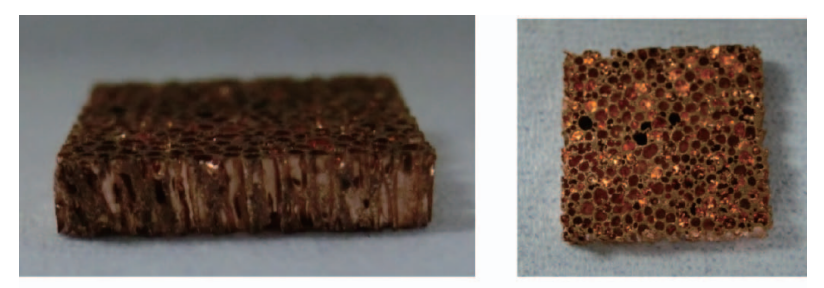

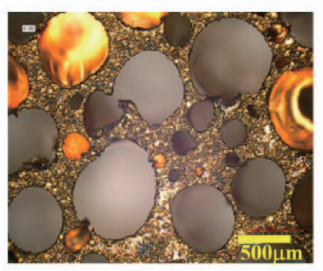

Before

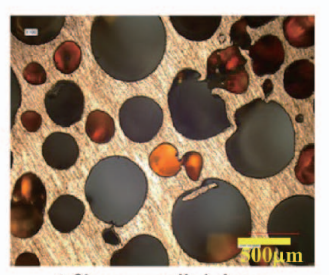

After polishing
Fig. 3 Surface structure of lotus copper.

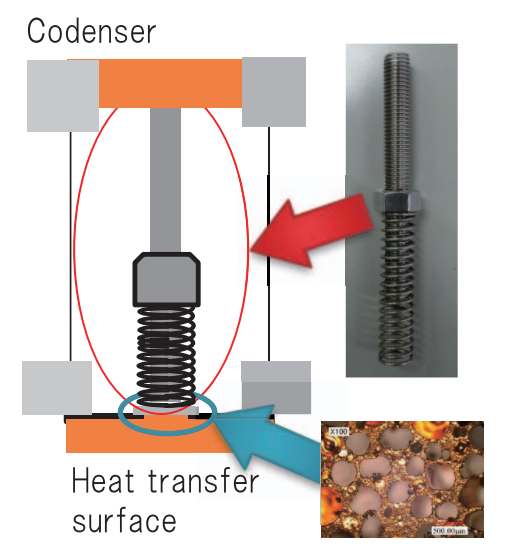

Fig. 4 Fixing of lotus copper with a spring.

transfer performance, hydrophilic material with the contact angle (for a water droplet) of $11^{\circ}$ is coated to the top surface and the side wall of the lotus holes in some cases of the mechanical contact. On the other hand, in the soldered case, a Sn-Ag solder sheet of $0.5 \mathrm{~mm}$ in thickness is set between the lotus copper plate and the heat transfer surface and then both are heated up to $250^{\circ} \mathrm{C}$ to connect each other. We confirmed that any melted solder doesn't get inside the lotus holes.

\section{Results and Discussion}

Figure 5 shows the boiling curves where the lotus copper plate is mechanically attached onto the heat transfer surface. The horizontal axis is the wall superheat $(\mathrm{K})$ that is temperature difference between the temperature of the heat transfer surface and the saturated temperature of water $100^{\circ} \mathrm{C}$. The legend "smooth surface" means bare surface without the lotus plate. For comparison, the value of the critical heat flux for saturated pool boiling, which is $110.9 \mathrm{~W} / \mathrm{cm}^{2}$, is represented based on Zuber's correlation. It is confirmed that the two boiling curves of the lotus cop- 


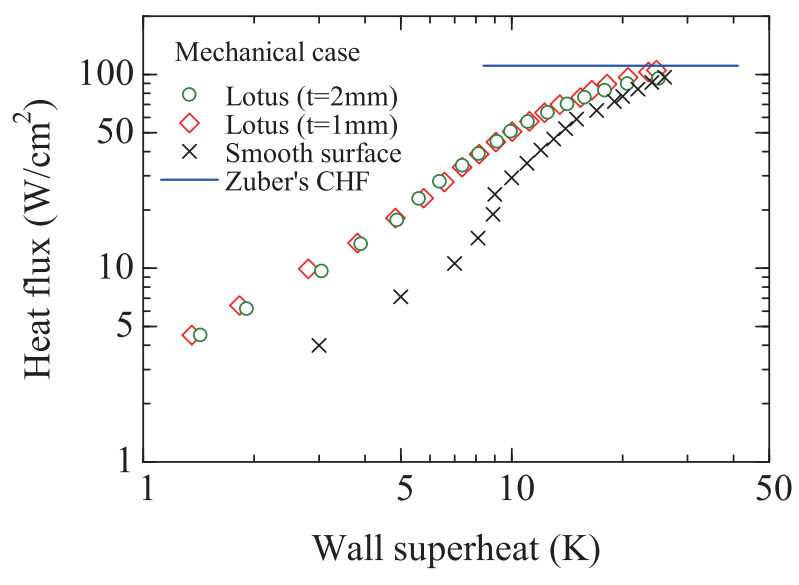

Fig. 5 Boiling curve of lotus copper.

per plate with the different thicknesses shift on lower wallsuperheat side compared with that of the smooth surface, which definitely proves the enhancement of the nucleate boiling heat transfer by utilizing the lotus copper plate. For instance, at the wall superheat of 5 to $10 \mathrm{~K}$, the heat flux for the lotus copper plates increases two to three times higher than that of the smooth surface. It is, however, impossible to confirm obvious difference of the thickness of the lotus copper plate. Comparing an enlargement rate of the heat transfer area of the lotus copper with that of the smooth surface, which is 5.4 , a heat transfer enhancing rate is much lower than the enlargement rate. Moreover, the critical heat flux when utilizing the lotus copper plate is almost the same as that of the smooth surface, regardless of the thickness of the lotus plate. This suggests us that the critical heat flux phenomenon where the lotus copper plate is mechanically attached to the heat transfer surface is similar to that of the smooth surface case. Judging from these facts, we can conclude that the contact thermal resistance between the lotus copper plate and the heat transfer surface is significant and that there could be a big temperature difference at the contact interface. In addition to that, if the contact thermal resistance was negligible, the heat transfer coefficient in the $2 \mathrm{~mm}$ thickness case could be higher than that in $1 \mathrm{~mm}$ thickness case (see Fig. 6). Also, author verified by experiments that the temperature gap at the interface of two flat surfaces exceeds $50 \mathrm{~K}$ without TIM under the heat flux conditions over $100 \mathrm{~W} / \mathrm{cm}^{2}$.[22] In that sense, the temperature of the lotus copper plate is almost saturated temperature of water and the boiling phenomena could be dominant at the bottom of the lotus holes. Regarding the heat transfer coefficient as shown in Fig. 6, the nucleate boiling heat transfer performance becomes higher with the increase in the wall superheat, and, then, the heat transfer coefficient slowly deteriorates

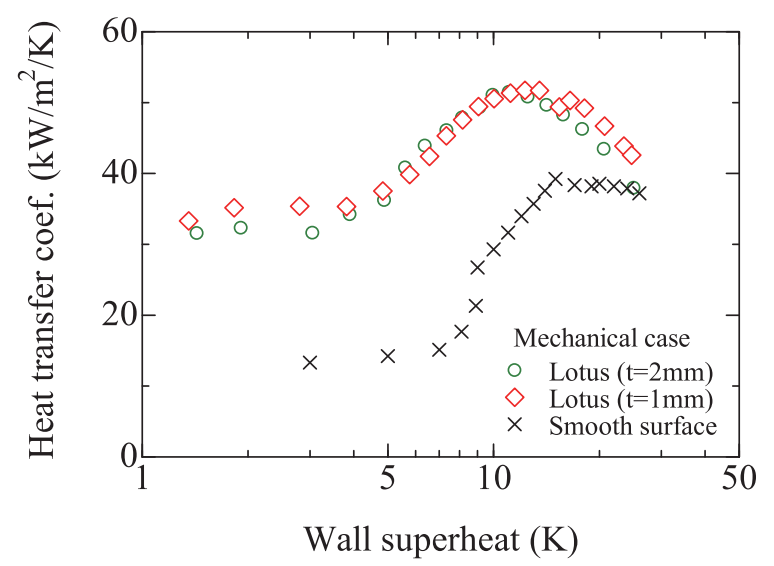

Fig. 6 Heat transfer characteristics of lotus copper.

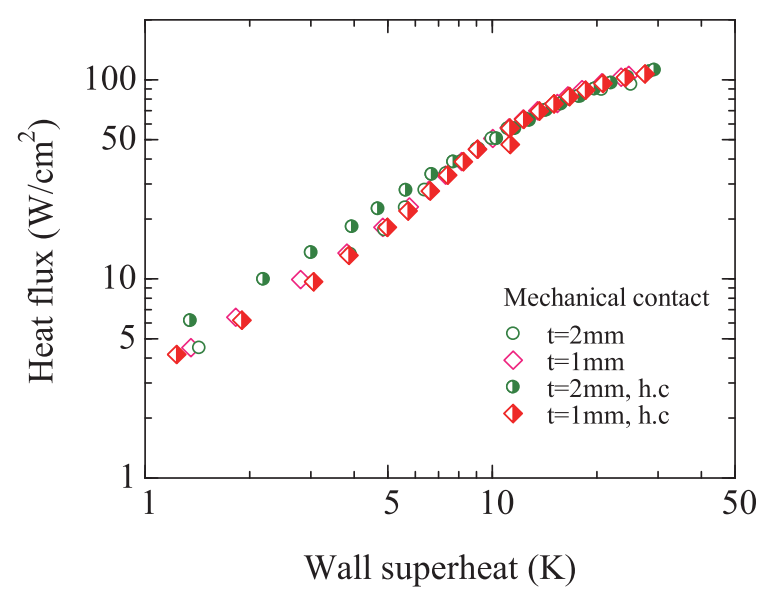

Fig. 7 Heat transfer characteristics of lotus copper with hydrophilic coating.

after the wall superheat of $10 \mathrm{~K}$. This is probably because each lotus pore hole is gradually being filled with the vapor bubbles, which also inhibits the liquid from being supplied into the holes. In order to confirm the liquid supply and verify this assumption under somewhat forced liquid supplying condition, the side walls of each lotus pore hole are coated with hydrophilic material that can work even at high temperatures up to $150^{\circ} \mathrm{C}$. Figure 7 shows the heat transfer characteristics with the hydrophilic coating. There is no significant effect of the hydrophilic coating on the nucleate boiling heat transfer as well as the critical heat flux, which proves that the liquid is being supplied into the lotus holes even without the hydrophilic coating. Furthermore, new nucleation sites seem not to be activated on the side wall of the lotus holes, which also indicates us that there is the contact thermal resistance between the lotus copper plate and the heat transfer surface. As the average hydraulic pore diameter of the lotus copper plate in this experiment is $0.36 \mathrm{~mm}$, which has weak effect for both the liquid supply by the capillary force toward the bottom of the pore hole and activated cavity for boiling, heat transfer 


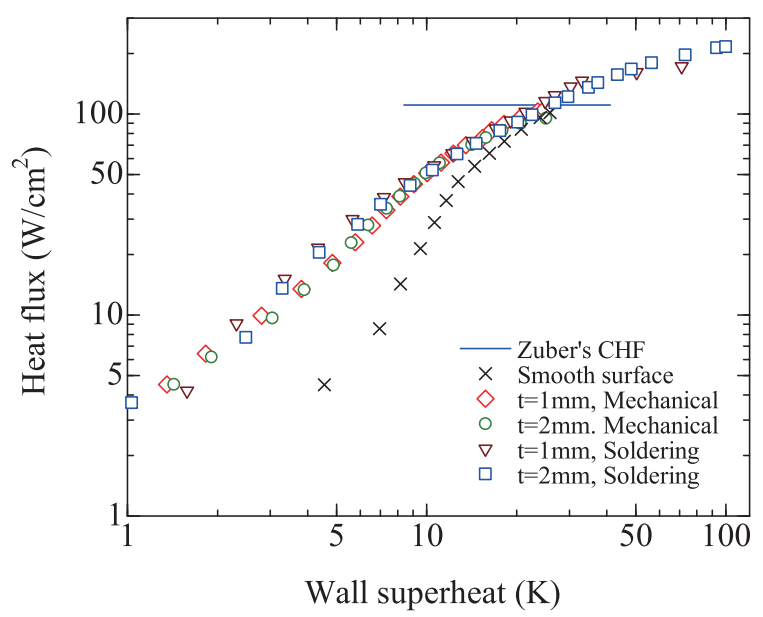

Fig. 8 Critical heat flux improvement by soldering lotus copper.

experiments should be conducted by utilizing the lotus copper plate with smaller pore diameters in the future for comparison. On the other hand, Fig. 8 shows effect of soldering the lotus copper onto the heat transfer surface on the boiling curve. Although the trend of the boiling curves in the soldering cases are almost similar to those in mechanically attached case especially in the nucleate boiling regime, the critical heat flux in both the cases with different thicknesses drastically increases. The critical heat fluxes for the thickness of $1.0 \mathrm{~mm}$ and $2.0 \mathrm{~mm}$ are $172 \mathrm{~W} /$ $\mathrm{cm}^{2}$ and $216 \mathrm{~W} / \mathrm{cm}^{2}$, respectively. The latter value is almost double of that in the smooth surface case, which suggests the contact thermal resistance between the lotus copper plate and the heat transfer surface is eased and the heat flows inside the lotus copper. In order to further increase the critical heat flux beyond $300 \mathrm{~W} / \mathrm{cm}^{2}$, the liquid supply toward the hole inside should be discussed.

\section{Conclusion}

This study evaluated boiling heat transfer performance on a lotus-type of porous copper plate attached onto a heated surface. The experiments were performed under atmospheric pool conditions. The lotus copper plates have uni-directional pore structure in a perpendicular direction for the heated surface. The lotus porous plate was mechanically attached or soldered onto the heated surface in order to obtain the referential boiling heat transfer data of these lotus porous plate. The boiling curves suggested that the utilization of the lotus copper plate lead to boiling heat transfer enhancement especially in a low heat flux regime. However, the thickness of the lotus plate didn't affect the boiling heat transfer coefficient in the mechanically attached case, which indicates that there is a big con- tact thermal resistance between the heated surface and the lotus copper plate. In addition, it was confirmed that the critical heat flux in the mechanically attached case was almost the same as that in the smooth surface case. On the other hand, the critical heat flux drastically increased up to $216 \mathrm{~W} / \mathrm{cm}^{2}$ by soldering the lotus copper plate onto the heat transfer surface, which is almost double of that in the smooth surface case. In order to further increase the critical heat flux beyond $300 \mathrm{~W} / \mathrm{cm}^{2}$, the liquid supply toward the hole inside should be discussed.

\section{References}

[1] H. Maeda, H. Kubo, H. Torimori, and R. Tamura, "System Packing Technologies for the K computer," FUJITSU, Vol. 63, No. 3, pp. 265-272, 2012.

[2] K. Yuki, "Cooling Technology for the Next Generation $\mathrm{SiC}$ On-Vehicle Inverters,” Journal of The Japan Institute of Electronics Packing, Vol. 18, No. 2, pp. 94-99, 2015.

[3] S. G. Kandlikar, Chapter 3 - Single-Phase Liquid Flow in Minichannels and Microchannels, Heat Transfer and Fluid Flow in Minichannels and Microchannels (Second Edition), Elsevier, pp. 103-174, 2014.

[4] T. Dixit and I. Ghosh, "Review of micro- and minichannel heat sinks and heat exchangers for single phase fluids," Renewable and Sustainable Energy Reviews, Vol. 41, pp. 1298-1311, 2015.

[5] K. Yuki and K. Suzuki, "Applicability of Minichannel Cooling Fins to the Next Generation Power Devices as a Single-Phase-Flow Heat Transfer Device," Transactions of The Japan Institute of Electronics Packaging, Vol. 4, No. 1, pp. 52-60, 2011.

[6] D. Lorenzini, C. Green, T. E. Sarvey, X. Zhang, Y. Hu, A. G. Fedorov, M. S. Bakir, and Y. Joshi, "Embedded single phase microfluidic thermal management for non-uniform heating and hotspots using microgaps with variable pin fin clusteringOriginal," International Journal of Heat and Mass Transfer, Vol. 103, pp. 1359-1370, 2016.

[7] Y.-T. Mu, L. Chen, Y.-L. He, and W.-Q. Tao, "Numerical study on temperature uniformity in a novel minichannel heat sink with different flow field configurations," International Journal of Heat and Mass Transfer, Vol. 85, pp. 147-157, 2015.

[8] J. F. Tullius, T. K. Tullius, and Y. Bayazitoglu, "Optimization of short micro pin fins in minichannels," International Journal of Heat and Mass Transfer, Vol. 55, Issues 15-16, pp. 3921-3932, 2012. 
[9] S. A. Jajja, W. Ali, H. M. Ali, and A. M. Ali, "Water cooled minichannel heat sinks for microprocessor cooling: Effect of fin spacing," Applied Thermal Engineering, Vol. 64, Issues 1-2, pp. 76-82, 2014.

[10] Y. Fan, P. S. Lee, L.-W. Jin, B. W. Chua, and D.-C. Zhang, "A parametric investigation of heat transfer and friction characteristics in cylindrical oblique fin minichannel heat sink," International Journal of Heat and Mass Transfer, Vol. 68, pp. 567-584, 2014.

[11] K. Nishikawa, T. Ito, and K. Tanaka, "Enhanced Heat Transfer by Nucleate Boiling at Sintered Metal Layer, Refrigeration,” Vol. 53, No. 612, pp. 905-910, 1978.

[12] T. Ito, K. Nishikawa, and K. Tanaka, "Evaluation of Potential High Performance Porous Boiling Surface (First Report),” Refrigeration, Vol. 57, No. 651, pp. 25-29, 1982.

[13] K. Cornwell, B. G. Nair, and T. D. Patten, "Observation of boiling in porous media, International Journal of Heat and mass transfer," Vol. 19, No. 2, pp. 236238, 1976.

[14] M. Fujii, "Nucleate Pool Boiling Heat Transfer from Porous Heating Surface (Optimum Particle Diameter)," Transaction of the Japan Society of Mechanical Engineers, Series B, Vol. 50, No. 451, pp. 818-824, 1984.

[15] G. S. Hwang and M. Kaviany, "Critical Heat Flux in Thin Uniform Particle Coatings," International Journal of Heat and Mass Transfer, Vol. 49, pp. 844-849, 2006.

[16] H. Asano, et al., "A study on Nucleate Boiling Heat Transfer Enhancement by Thermal Spray Coating
(Result of Pool Boiling Experiments under Microgravity)," Progress in Multiphase Flow Research I, pp. 103-109, 2006.

[17] H. Sakamoto and K. Mikubo, "Effects of Copper Plating on Boiling Heat Transfer," Proceedings of the International Conference on Electronics Packing 2007, 2007.

[18] C. M. Patil and S. G. Kandlikar, "Review of the Manufacturing Techniques for Porous Surfaces Used in Enhanced Pool Boiling,” Heat Transfer Engineering, Vol. 35, No. 10, pp. 887-902, 2014.

[19] S. Mori and K. Okuyama, "Enhancement of the Critical Heat Flux in Saturated Pool Boiling Using Honeycomb Porous Media,” International Journal of Multiphase Flow, Vol. 35, pp. 946-951, 2009.

[20] H. Chiba, T. Ogushi, et al., "Heat Transfer Capacity of Lotus-type Porous Copper Heat Sink for Air Cooling,” Journal of Thermal Science and Technology, Vol. 5, No. 2, pp. 222-237, 2010.

[21] H. Chiba, T. Ogushi, and H. Nakajima, "Development of Heat Sinks for Air Cooling and Water Cooling Using Lotus-Type Porous Metals,” Proceedings of the ASME/JSME 2011 8th Thermal Engineering Joint Conference, Paper No. AJTEC2011-44108, ISBN:978-0-7918-3892-1, 2011.

[22] K. Yuki, K. Takai, Y. Indo, and K. Suzuki, "Proposal of utilizing uni-directional porous metal for extremely high heat flux removal," Proceedings of the 6th International Conference on Porous Media and Its Applications in Science and Engineering (ICPM6), 2016. 


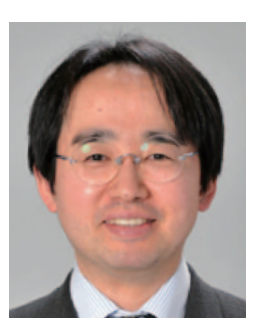

\section{Kazuhisa Yuki}

Professor of Tokyo University of ScienceYamaguchi, Ph.D.1998 (Kyushu University), 1998-2009 Tohoku University, Research on cooling technology of high heat flux equipment such as electronics and energy devices utilizing metal porous media, micro \& minichannel, nano technology etc. (http://www.tusy.ac.jp/ departments/teacher/kazuhisa-yuki.html)

\section{Tomohiro Hara \\ Soichiro Ikezawa \\ Kentaro Anju}

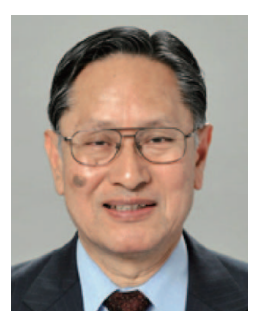

\section{Koichi Suzuki}

Professor Emeritus of Tokyo University of Science-Yamaguchi, Ph.D.1989 (Tokyo University of Science), Research on boiling heat transfer and advanced high heat flux cooling system for power electronics. A leading researcher on Microbubble Emission Boiling (MEB) in the world.

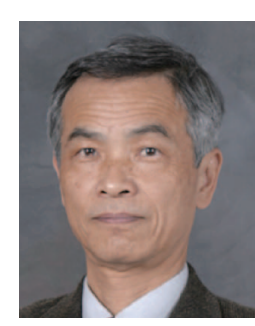

\section{Tetsuro Ogushi}

Technical adviser of Institute for Lotus Materials Research co., ltd and Advanced Knowledge Laboratory, Inc., Ph.D.1987 (Kyushu University), 1971-2007 Mitsubishi Electric Corp. 2007-2013 Hiroshima International University, Research on heat transfer region of cooling technique of electronics equipment, heat pipe and thermal conductivity measurement method.

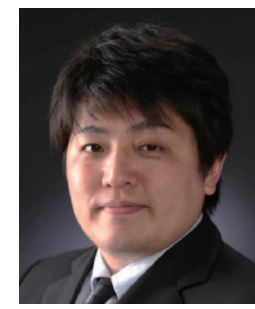

direction
Takuya Ide

Member of the Board of Directors Chief Technology Officer of Institute for Lotus Materials Research co., 1td. Ph.D.2005 (Osaka University), 2005-2011 Osaka University, Research on fabrication porous metal with directional pore aligned one

\section{Masaaki Murakami}

